\title{
A EDUCAÇÃO DO CAMPO COMO MODO DE RESISTÊNCIA À INVESTIDA NEOLIBERAL: RELATO DE EXPERIENCIA DE UM FAZER ESCOLA NO ASSENTAMENTO DO MST
}

\author{
COUNTRYSIDE EDUCATION AS RESISTANCE TO NEOLIBERAL \\ THRUST: A SCHOOL-BUILDING EXPERIENCE AT A SETTLEMENT \\ OF THE BRAZIL'S LANDLESS WORKERS MOVEMENT.
}

\begin{abstract}
Marcia Roxana Cruces Cuevas ${ }^{1}$
Maria de Fátima Miguel Ribeiro ${ }^{2}$

RESUMO

O neoliberalismo tem acelerado a mercantilização da educação e das políticas públicas conquistadas pela população brasileira desde o fim da ditadura militar. No estado do Espírito Santo, este processo foi ampliado desde a segunda gestão do governo de Hartung, mediante o fechamento de escolas do/no campo. O objetivo deste artigo é analisar as práticas de resistência de educadores e educandos da EEEF Paulo Damião Tristão Purinha, do assentamento Sezínio Fernandes de Jesus, no município de Linhares, no estado do ES, para dar visibilidade ao processo de afirmação da vida dos trabalhadores em suas atividades de resistência e nos princípios filosóficos, pedagógicos e políticos que afirmam no plano de estudos, na auto-organização, na agroecologia e mística como práticas formativas que se dão desde o chão da escola.
\end{abstract}

Palavras-chave: Educação do Campo; Resistência; Coletivo; MST.

\begin{abstract}
Neoliberalism has accelerated the commodification of education and of the public policies conquered by the Brazilian people since the end of the military dictatorship. In the state of Espirito Santo, this process has been expanded by closing schools in the countryside since the second administration of Hartung's government. This article aims to analyze the resistance practices at the Paulo Damião Tristão Purinha State Elementary School in the Sezinio Fernandes de Jesus settlement. With that, we hope to give visibility to the process of affirming workers' lives in their resistance actions. These include their philosophical, pedagogical, and political principles, demonstrated in the syllabus, in the self-organization, in the agroecology, and "místicas," as formative practices since the school floor.
\end{abstract}

Keywords: Rural Education; Resistance; Collective; MST.

\footnotetext{
${ }^{1}$ Atualmente é professora do Curso de Psicologia da Universidade Federal do Espírito Santo. Doutora em Educação pela Universidade Federal do Espírito Santo. Mestra em Psicologia pela Universidade Federal do Espírito Santo. e-mail: marcia.roxana@ hotmail.com

${ }^{2}$ Graduada em Pedagogia pela Universidade Federal do Espírito Santo. Mestre em Psicologia Institucional pela UFES. e-mail: fatimamiri@yahoo.com.br
} 


\section{INTRODUÇÃO}

Desde 2014 as condições internacionais tinham mudado e a recessão se aprofundado no Brasil e, segundo Sader (2016), apesar dos investimentos do governo à época, que buscou manter as políticas sociais como forma de combate às desigualdades, à pobreza e miséria via a ampliação do consumo, a economia chegou quase a ficar parada. Diante disso, as forças conservadoras foram se aglutinando e buscando apoio popular de forma a enfraquecer o governo recém-eleito, acabando, em 2016, pela votação do impeachment contra a presidenta eleita Dilma Rousseff.

Em 2018, vivemos nova eleição que acabou por colocar na Presidência o candidato que se mostrou autoritário em sua atuação política. Segundo análises em curso, colocadas a partir da obra de Levitsky e Ziblatt ${ }^{3}$, apresentadas por Singer (2018), o novo presidente do Brasil

\section{[...] questiona as leis democráticas, elogiando frequentemente a ditadura militar brasileira. Tem como vice um general que ameaçou dar um autogolpe. Encoraja a violência por meio de execuções extrajudiciais pela polícia. Nega a legitimidade de seus oponentes, tendo declarado que Fernando Henrique Cardoso deveria ter sido morto durante a ditadura militar, que Lula deveria ter sido preso e que seu governo tratará o MST como terrorista. Se mostra disposto a restringir as liberdades civis aprovando a tortura (SINGER, apud LEVITSKY; ZIBLATT, 2018).}

Singer (2018) em sua análise empírica destaca a existência real de ameaça à democracia brasileira diante das declarações feitas pelo, agora, presidente eleito. Em tão pouco espaço de tempo de governo (apenas se passaram dez meses desde que assumiu o governo) já sentimos em nossos corpos e relações, os efeitos da política neoliberal que ameaça os direitos dos trabalhadores, as conquistas mais elementares da constituição de 1988, como os direitos trabalhistas, previdenciários, a soberania nacional e a reforma agrária. Nos dez primeiros meses temos acompanhado, com decepção e tristeza, o entreguismo e favorecimento do capital externo na compra de bens públicos. E mais, a violência de todos os tipos que se tem se alastrado em todo nosso território. É só olhar para a cidade do Rio de Janeiro, onde o Estado, na figura de

\footnotetext{
${ }^{3}$ Professores da Universidade de Harvard com olhar liberal.
} 
seu governador o Sr. Witzel, comemorou recentemente a morte de um sequestrador de ônibus (NOGUEIRA, 2019) $)^{4}$.

Nesse contexto, a ampliação do estado mínimo, o estado neoliberal, confirma-se como um horizonte que já veio tomando forma e se ampliando desde as últimas eleições, via acordos estabelecidos junto a grandes grupos econômicos que historicamente aplicam

[...] a doutrina do ajuste e da austeridade que se produz pela ampliação da exploração do trabalhador, corte de direitos, difamação e desmanche do que é público e de políticas universais. Doutrina que, para sua manutenção de sua agressividade, desliza para a criminalização daqueles que se opõem e na anulação do Estado de direito e a montagem de um Estado policial (FRIGOTTO, 2017, p. 25).

Segundo o autor acima, esse contexto policialesco, contaria com mais um tempero, a composição dominante no Parlamento que se tem aliado às ideias fundamentalistas religiosas, que fortalecem a lógica do mercado, prolongando e espalhando essas ideias a todos os cantos do país.

Diante dessa ação policialesca do Estado neoliberal, os movimentos sociais tem experimentado ataques de toda ordem, fazendo com que a luta e a resistência continuem proliferando, mesmo quando o Estado não escuta, não olha e ignora totalmente as demandas da população que continua ocupando as ruas e organizando a luta e defesa de uma educação pública, de qualidade, e para todas (os).

A Educação do Campo, nesse contexto, tem enfrentado os diversos embates com a insistente e constante criação de resistências, mantendo e ampliando as ações da Pedagogia da Terra nas escolas no e do campo e a luta, que passa pela afirmação de uma gestão escolar democrática, por princípios educativos e filosóficos do campo e sua forma de fazer a educação.

Ser militantes e educadoras nesta conjuntura, agora mais do que nunca, tem significado fazer brotar forças de onde não se sabe que se tem, para revigorar no encontro com outras forças de educadoras (es). Desse modo, temos buscado ocupar o espaço público compondo com

\footnotetext{
${ }^{4}$ A Folha de São Paulo chamou à ação do Sr. Governador como "as cenas mais dantescas da política fluminense". O jornal destaca, ainda, a frase que o Governador expressou friamente ao olhar para a câmera: "Não sai de fuzil na rua, não. Troca por uma bíblia, se você sair com um [com um fuzil], nos vamos é te matar!" (NOGUEIRA, 2019).
} 


\section{Revista \\ Debates Insubmissos}

diversos coletivos, de forma a operar como uma usina, produzindo forças, contagiando e fortalecendo um projeto de sociedade e de vida para todas(os). Constituir-se na luta e na militância de uma outra sociedade, nos coloca diante de muitos desafios, sendo a produção do coletivo um dos mais presentes no atual momento, já que as rachaduras internas diante do excesso de ações e demandas, o empobrecimento da vida, das relações, diante de poucos espaços de encontro e diálogo, nossos corpos sentem assim, muitas vezes, sufocados, mas não desistimos. Insistimos, o projeto é grandioso e a causa é imensa!

Nos diversos encontros vividos, sentimos que os acúmulos da experiência, a criação de estratégias coletivas para contornar as situações e fortalecer a organização, muito tem animado e constituído a própria resistência. Assim, afirmamos que fazer educação e militar em defesa da educação pública hoje é, constituir-se movimento, estando atenta(o) aos novos desafios, percebendo as sutilezas da cooptação e da desarticulação de coletividades que se mostra em ações que fortalecem um projeto individual em detrimento de um social.

Este artigo faz parte da investigação que realizamos em âmbito de mestrado ${ }^{5}$ que busca a construção de um conhecimento que brota na/da realidade concreta, nos/dos afazeres cotidianos vividos em busca de um saber da/para a vida. Na realização da pesquisa assumimos operar com as ferramentas da Análise Institucional e, assim, fazer análise de nossa implicação no processo formativo que se dá, ao militar, ao viver e ao conhecer concomitantemente.

Desse modo, no decorrer do trabalho da escrita deste artigo, nos colocamos diante de uma série de questões, repensamos nossas práticas, escolhas e relações o exercício e ofício docente $^{6}$. Assim, neste artigo, buscamos analisar as práticas de resistência de educadores e educandos da EEEF Paulo Damião Tristão Purinha, do assentamento Sezínio Fernandes de

\footnotetext{
${ }^{5}$ A pesquisa tem como título: "A resistência inventiva da escola do campo frente a ofensiva do Estado" é realizada no Programa de Pós-Graduação em Psicologia Institucional da UFES. Na pesquisa partimos das perguntas: Como se constituem os processos de criação, invenção, de afirmação da vida nas práticas de organização e trabalho educacional na Educação do Campo do Movimento dos Trabalhadores Rurais Sem Terra/MST, na atual conjuntura neoliberal, consolidada desde antes do processo eleitoral recentemente vivido no Brasil e, no nosso estado do Espírito Santo? Como resistir a tamanhos golpes ${ }^{5}$, sobretudo na Educação do Campo. A previsão é encerramento em maio de 2020.

${ }^{6}$ Referimo-nos ao ofício docente porque reconhecemos no trabalho docente uma técnica, habilidade e especialização necessárias ao seu trabalho.
} 
Jesus, no município de Linhares, no estado do ES, para dar visibilidade aos processos de afirmação da vida que se dão nesse movimento de acirramento das forças ultraconservadoras.

Assumimos a luta pelo direito à educação pública como permanente convocação para abrir sulcos nela mesma, ou seja, fazer da luta por/pela/na educação um meio e veículo para novas práticas que se fortalecem na resistência, na medida que desagrega a própria educação, ampliando-a (HECKERT, 2004).

As resistências se gestam no cotidiano da vida e, para Foucault (1983), elas se engendram no "ronco surdo da batalha", ou seja, no meio das batalhas, por meio de ações menores, que nos tiram das capturas pessimistas que acabam afirmando o medo. Ou seja, falar de resistência significaria falar de

[...] uma instalação que se dá no meio - lugar onde forças turbulentas engendram fabulações mesmo que silenciosas [...] não há um espaço privilegiado em que esses processos irrompam. Às vezes, eles se tramam nas salas anexas aos gabinetes de veludo; por vezes nos próprios gabinetes. Podem também estar sendo gestados nas salas de aula, nos corredores das escolas, nos refeitórios, nas janelas, por entre os muros, nas esquinas [...] resistir, como re-existência, criação de modos de agir que afirmam a inesgotável potência de criação que constitui o vivo (HECKERT, 2004, p. 14 e 15. Grifos nossos)

E, nesse desafio colocado por Heckert (2004) e assumido por nós, escrevemos este artigo buscando afirmar ações que ampliam a luta por uma Educação do Campo que, diante das impossibilidades, cria outros modos de agir.

A reinvenção e a resistência são práticas fortes e insistentemente praticadas pelas lutadoras e lutadores da Educação do Campo, em sintonia com a luta por reforma agrária popular, que não se entrega diante de tantas seduções e ameaças da ordem capitalista/neoliberal.

Ainda, junto com Freire (1992) sentimos que,

É que a "democratização" dá sem vergonhice que vem tomando conta do país, o desrespeito à coisa pública, a impunidade se aprofundaram e se generalizaram tanto que a nação começou a se pôr de pé, a protestar. Os jovens e os adolescentes [as crianças, idosos e adultos] também, vêm às ruas, criticam, exigem seriedade e transparência. O povo grita contra os testemunhos de desfaçatez. As praças públicas de novo se enchem. Há uma esperança, não importa que nem sempre audaz, nas esquinas das ruas, no corpo de cada uma e de um de nós. É como se a maioria da nação fosse tomada por incontida necessidade de vomitar em face de tamanha vergonha (FREIRE, 1992, p. 4). 
E diante dessa "democratização da sem vergonhice" assumimos com Freire (2000) a necessidade de atuar no presente, na luta cotidiana, encarada como invenção de outros modos de fazer a vida proliferar. Segundo Freire (2000, p. 27) “O futuro não nos faz. Nós é que nos refazemos na luta para fazê-lo".

\section{COMO FIZEMOS ESTE ESTUDO?}

Pensamos um outro modo de fazer pesquisa, a partir do chão da escola e do contexto de uma organização social que se move e se envolve constantemente na busca da proliferação vida, a partir da educação dos camponesas(es) e assentadas(os) da reforma agrária. Não podemos colocar-nos diante da produção do conhecimento assumindo a neutralidade no viver e fazer o conhecer.

Assumimos o caminho metodológico proposto por Romagnoli e Paulon (2014) que se situa no meio dos processos para criar outros mundos possíveis, sustentar outras dimensões e

perspectivas múltiplas. Desse modo, escolhemos trabalhar com a pesquisa-intervenção que, como ação concreta, tateia, inventa dispositivos produtivos que afirmam o conhecer desde sua ação (PASSOS; BARROS, 2009).

Segundo os autores, esta metodologia se constitui no "caminho metodológico" quando se orienta por "um saber que vem, que emerge do fazer" (p.18), direcionando o trabalho de pesquisa para o fazer-saber.

Romagnoli e Paulon (2014) nos apontam que é preciso neste tipo de pesquisa nas contribuições de René Lourau no que ele designa de "análise da implicação",

Fazer a análise das implicações indica que vínculos (afetivos, históricos, sexuais, profissionais) estão sendo postos em jogo numa determinada situação. Mas ainda, cria passagem, através de sua historicização, para as virtualidades já presentes, mas invisíveis aos sujeitos. Dessacraliza-se, desta forma, os rituais instituídos e de puro domínio do analista. Coletiviza-se a análise. Singulariza-se por outro lado, cada situação em análise (ROMAGNOLI; PAULON, 2014, p. 26). 


\section{Revista \\ Debates Insubmissos}

Como colocado pelos autores acima, em Lourau, há necessidades de indagarmos acerca dos instituídos cristalizados nos campos de investigação/intervenção, pois não há possibilidades se efetuar uma análise apolítica de qualquer instituição.

A partir das argumentações apresentadas nos perguntamos acerca dos movimentos que são constituídos no âmbito micro e macropolítico neste contexto neoliberal assumido no Brasil atual. Assumimos o desafio de produzir uma análise que incorpore ambas dimensões da vida e da organização social. Desse modo, nos interessa compreender o movimento da militância que insiste na criação de novas formas de resistir à regulação estatal.

Desse modo, nos propomos habitar o território da Educação do Campo nos posicionando ao meio dos processos de formação, luta e educação de forma a enxergar novas subjetividades que estão sendo gestadas no chão da escola, estando diretamente articulados com os educadores, integrando-se com os educandos e educandas e se fazendo presente na comunidade. Significa estar atento para as novidades, desde longe ou de perto das vizinhanças, sendo parte desse trabalho (BARROS; KASTRUP, 2009. p. 56).

Acompanhamos o cotidiano da Escola Estadual de Ensino Fundamental Paulo Damião Tristão Purinha que é fruto da luta de mais de 350 famílias que lutaram para conquistar a Fazenda Aliança, no município de Linhares, ocupando pela primeira vez no dia 09 de outubro de 1997. Hoje o assentamento Sezínio Fernandes de Jesus, conta com 2.042 hectares, com 100 famílias, aproximadamente 700 pessoas (EEEF PAULO DAMIÃO TRISTÃO PURINHA, 2018).

A partir de uma intensa luta para conquistar a terra, as famílias insistiram por uma escola para seus filhos. Em 2008 a escola para filhos de assentados foi criada, com uma organização intensa que envolveu as famílias assentadas e o Setor Estadual de Educação do MST. Inicialmente começou a atender as crianças de $1^{\circ}$ ao $5^{\circ}$ ano, depois do $6^{\circ}$ ao $9^{\circ}$ ano e Educação de Jovens e Adultos/EJA. Atualmente, atende as comunidades vizinhas, fazendas e o distrito de Humaitá. Iniciou em 2018 com 115 educandos e educandas (EEEF PAULO DAMIÃO TRISTÃO PURINHA, 2018). 
Nesse contexto, os dados da pesquisa foram produzidos participando nas atividades no movimento coletivo, tais como: auto-organização, mística, critica e autocrítica, plano de estudo, atividades de pesquisa e agroecologia que a escola propõe, na sala de aula, nas reuniões, estando junto e, assim, colocamos em análise as práticas coletivas existentes. Debater, colocamos em analise as práticas, os espaços, as histórias e as ações, participando das diversas atividades e nos deixando "ser afetado por aquilo que os afeta", estar assim no mesmo plano intensivo desse território existencial (BARROS; KASTRUP, 2009, p. 61).

Os dados produzidos foram trabalhados segundo a análise do discurso Foucaultiana que nos orienta a tratar os discursos como práticas e que, diante delas, necessitaremos simplesmente ficar no nível da existência das palavras, evitando a interpretação que, afinal, confirma uma essência anterior à própria produção das práticas. Assim Foucault nos fala:

[...] não mais tratar os discursos como conjunto de signos (elementos significantes que remetem a conteúdos ou a representações), mas como práticas que formam sistematicamente os objetos de que falam. Certamente os discursos são feitos de signos; mas o que fazem é mais que utilizar esses signos para designar coisas. É esse mais que os torna irredutíveis à língua e ao ato da fala. É esse mais que é preciso fazer aparecer e que é preciso descrever (FOUCAULT, 1986, p. 56. Grifo nosso).

Nesse sentido, na escrita do diário de campo buscamos descrever, fazer aparecer o que ainda pulsa nas lutas de resistência pela manutenção e ampliação da Educação do Campo.

\section{O QUE TEMOS VIVIDO NO ESTADO DO ESPÍRITO SANTO, NO ÂMBITO DA EDUCAÇÃO DO CAMPO?}

Em 2014 foi reeleito, pela terceira vez para governar o Estado, o Sr. Paulo Hartung que se tem destacado no âmbito da administração pública como o governador que tem "sanado" as contas e exercido um governo austero, favorecendo o desenvolvimento econômico e social do Estado.

Segundo Oliveira Junior (2016), Paulo Hartung esteve à frente da gestão do Estado no passado, desde $1^{\circ}$ de janeiro de 2003, até 31 de dezembro de 2010, momento em que se viveu uma nova fase na reforma gerencial no Espírito Santo, ampliando a lógica do Estado Mínimo, o governo aproximou-se do grupo de empresários, garantindo a hegemonia econômica, política, 
social e educacional no Estado. O período de seu mandato foi marcado pela implantação de políticas públicas em consonância com a regulação do capital e dos anseios da economia capixaba em seu ciclo de desenvolvimento econômico, social e político, que está no projeto 2030 das ONGS Espírito Santo em ação (2013).

No âmbito da política educacional, o governo Paulo Hartung, impôs uma nova relação entre o governo a sociedade e os profissionais da educação. Segundo Oliveira Júnior (2016) foi neste

[...] período histórico sob o qual se realizou uma nova regulação do trabalho docente, com o agravamento de sua precarização, em que se predominou o ápice do projeto gerencial e tecnocrático na rede estadual de ensino do ES, sob a base das noções do produtivismo, desempenho, eficiência e eficácia (p. 90).

Foi no segundo mandato que, de acordo com o pesquisador acima, a educação foi alvo de ações políticas que restabeleceram o contrato da função social da escola, impondo uma nova relação entre governo, sociedade e profissionais da educação, gerando uma nova formatação do trabalho docente no Estado.

O terceiro mandato do governador veio para consolidar a política que se estabeleceu na parceria com um grupo de empresários do estado, os que propõem agendas e documentos norteadores para as ações no Estado, grupo denominado "Espírito Santo em Ação". A esse respeito, Oliveira e Lírio (2017) afirmam

Tal fenômeno ocorre em um contexto de forte hegemonia da concepção urbanoindustrial, a qual busca atender a interesses ancorados na agenda da ONG ES em ação, organismo que congrega diversas empresas de grande porte e que controla a agenda política capixaba, impondo ao conjunto do Estado o seu projeto de desenvolvimento econômico e social.

O objetivo desse grupo de empresários é a ampliação de um projeto de estratégia econômica, social e política que vai até o ano de 2030. E, questões relativas à educação e às mudanças administrativas na Secretaria de Estado da Educação/SEDU, estão em 3 (três) macroobjetivos, os quais se desdobram em 12 (doze) eixos estratégicos.

A educação está inserida no eixo cinco "Melhorar a qualidade dos serviços prestados à população e ampliar a sua oferta", destacamos abaixo 2 (dois) objetivos de este trecho do documento: 


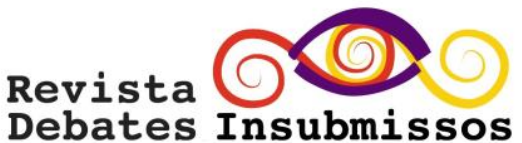

1. Melhorar de forma significativa os serviços públicos já prestados à população”. Apresentam-se quatro ações prioritárias definidas:

a. Reestruturar administrativa e pedagogicamente a SEDU, com foco na organização do trabalho escolar;

b. Promover a descentralização administrativa por meio da gestão compartilhada com os municípios;

c. Expandir o ensino médio;

d. Combater o analfabetismo de forma efetiva e contemporânea.

2. Incluir novos serviços, com conceitos atualizados que melhorem o atendimento à população, com três itens:

a. Promover a democratização da gestão, do acesso à escola e do acesso ao conhecimento;

b. Valorizar a educação rural;

c. Reestruturar a segurança escolar e o transporte escolar. (ESPÍRITO SANTO, 2003, p. 39).

Ainda, a partir de 2016 o Governo do Estado, através do Secretário de Educação, introduziu em sua gestão o Banco Itaú e Bradesco para desenvolver uma série de mudanças pedagógicas e administrativas que vieram consolidando uma "nova" política educacional capixaba que se iniciou no seu segundo mandato, uma educação subordinada aos grupos empresariais e que afetou e afeta drasticamente a existências das escolas de ensino médio em detrimento à introdução da "Escola Viva"

Oliveira e Lírio (2017, p 1) destacam que

[...] a política educacional do Governo Paulo Hartung, materializada no Programa Escola Viva, representa uma escalada rumo ao processo de privatização do sistema público de ensino do Espírito Santo e resulta de um processo antidemocrático, uma vez que não foi fruto de diálogo com a sociedade, mecanismo que consideramos mais adequado para a implementação de políticas públicas na área da educação.

Os dados apontam que a política do Governo Paulo Hartung no âmbito da Educação no Estado do Espírito Santo e, de modo específico a Educação do Campo, tem estimulado e ampliado o desmonte da educação pública capixaba. O governo de Sr. Paulo Hartung, em sua terceira gestão fechou 42 escolas entre 2015 a 2018. Ainda, no que se refere às vagas disponíveis na rede estadual, passaram de 497.498 em 2014, para 282.983 em 2018, uma

\footnotetext{
${ }^{7}$ Nome da escola da gestão de Hartung que segue as mudanças implementadas para o ensino médio.
} 
redução de 43,12\% no período. Uma política de desmonte que começou a ser implantada em 2015 e segue seu curso. ${ }^{8}$

Os dados acima mostram que a educação pública não tem sido prioridade das gestões do governo Paulo Hartung, mesmo porque os "fechamentos que foram justificados como ajustes, nada mais vieram atender aos anseios da política neoliberal promovida e pela opção de sempre pender pelos lenitivos do estado mínimo" (CARDOSO; SANTOS, 2018, p. 298).

\subsection{Resistir, fortalecendo o modo de vida coletivo}

Desde 2015 há um processo de mobilização das famílias assentadas defendendo a manutenção das escolas dos/nos assentamentos, denunciando seu fechamento. O movimento social entende que é crime o fechamento destas e reivindica ação na SEDU para que, através da Superintendência de Educação de São Mateus, respeite as conquistas das organizações no campo diante da Pedagogia do Alternância9 .

Em 2016 a SEDU/ES elaborou um edital de contratação de professores e retirou o tempo de alternância das escolas. Essa medida afetou diretamente a folha de pagamento e o salário dos docentes do campo, pois houve uma redução de 50\% do provento dos educadoras(es). Também retirou as secretárias das escolas e ameaçou acabar com a função dos Coordenadores dos Assentamentos que coordenam, acompanham pedagógica e politicamente a gestão das escolas. Assim, o Secretário de Educação começou a fazer a chamada "nucleação" ou juntar as turmas de $1^{\circ}$ ao $5^{\circ}$ ano e do $6^{\circ}$ ao $9^{\circ}$ ano em outra turma.

\footnotetext{
${ }^{8}$ Dados apresentados pelo Deputado Estadual Sérgio Majeski - no dia 21 de fevereiro de 2018, na Assembleia Legislativa no ES, em audiência pública sobre o fechamento das escolas pelo governo Paulo Hartung.

${ }^{9}$ De acordo com suas origens metodológicas, a Pedagogia da Alternância é uma alternativa metodológica de formação profissional agrícola, em nível técnico, para jovens, inicialmente do sexo masculino, filhos de agricultores franceses. Consiste na articulação dos tempos na escola/TE e tempos na comunidade/TC. Onde os educandos permanecem duas semanas a dois meses, dependendo do curso, no espaço da escola, em regime de internato. No TC, os educandos retornam às suas propriedades familiares ou às comunidades ou aos assentamentos ou acampamentos de origem para colocar em pratica os conhecimentos que foram objeto de estudo no TE, a partir da problematização dos cultivos e do manejo da criação, feito no TC (PACHECO, 2016).
} 
Estas medidas intensificam as manifestações de denúncia das ações da SEDU/ES. Educadores, educandos e pais, levaram seus colchões, seus pertences e acamparam por dois dias na Superintendência Regional de São Mateus em fevereiro de 2016. Nessa ocupação se apresentou uma nova superintendente com trajetória profissional distante da realidade do/no campo e nenhuma participação social em movimento em defesa da Educação do Campo. Afirma não conhecer do assunto. Tudo era novo para ela e demonstrava que estava ali para cumprir as determinações da SEDU/ES. Quem estava reivindicando entendeu que essa profissional não encaminharia nenhuma demanda do movimento social.

As negociações não andavam e poderíamos dizer, na expressão popular, que a superintendente operava como um "sabonete escorregadio nas negociações", ou seja, estaria ali só para deslizar e não encaminhar nada. Diante disso, em assembleia geral, estudantes, educadores e comunidade geral, decidiram, por maioria, acampar na SEDU em Vitória ${ }^{10}$.

No dia 02 de fevereiro de 2016, as educadoras e educadores da reforma agrária, mais os representantes das comunidades, alguns educandos e educandas, ocuparam a sede da SEDU/ES, por volta de 8 horas e com palavras de ordem e cantos da terra e da escola do campo, iniciaram a resistência pela defesa da educação nas escolas dos assentamentos.

A manutenção do acampamento permanente no espaço da SEDU/ES na capital do estado e a manutenção do funcionamento das escolas nos assentamentos demandou muita organização e realização de trocas de educadores, rodízio no acampamento com os membros das comunidades e dos acampamentos mais próximos da Região Índio Galdino ${ }^{11}$, ação que mobilizou pelo menos cem (100) participantes. O acampamento na SEDU/ES aproximava-se

\footnotetext{
${ }^{10}$ Diversos meios de comunicação divulgaram as ações de resistência: "Ocupação da SEDU no ES: MST aposta em formação e diálogo com a sociedade como forma de resistência" (JORNAL SINDICAL, do dia 25 de fevereiro de 2016. Outra matéria informava "Movimentos sociais deixam prédio da Secretaria de Educação do ES" publicada em 11 de março desse mesmo ano. Outra matéria, desta vez no Jornal A Gazeta: "Justiça exige a reabertura de escolas, mas governo do ES nega fechamento". O site do MST publicava à época: "Sem Terra ocupam SEDU/ES após secretário ignorar pauta sobre educação" (MOVIMENTO DOS TRABALHADORES RURAIS SEM TERRA, 2019).

${ }^{11}$ São estruturas organizativas do Movimento dos Trabalhadores Rurais Sem Terra. Esta compõe os municípios de Linhares, Santa Tereza, Fundão e Aracruz. Municípios que tem acampamentos e assentamentos e estão localizados na região Serrana do estado do Espírito Santo, lócus da realização deste estudo.
} 


\section{Revista \\ Debates Insubmissos}

da organização geral do Movimento dos Trabalhadores Rurais Sem Terra/MST e da organização de suas escolas. Contavam com uma coordenação geral, com núcleos de dez (10) participantes e oito (8) equipes de trabalho, a saber:

1) Alimentação: responsável para organizar a alimentação de todos os acampados, desde o café da manhã, os lanches da manhã e tarde, almoço e janta. Esta equipe era responsável pela montagem da escala da organização da cozinha, assim como da sua distribuição;

2) Articulação política, responsável pela articulação política com as entidades sindicais, políticas, outros movimentos sociais, pastorais, juventudes e movimentos estudantis. Essa equipe era responsável em organizar a visita de lideranças de diferentes movimentos e organizar palestras nas igrejas e escolas da cidade de Vitória que demandassem;

3) Equipe de Comunicação, foi responsável pelo contato com os jornais e a organização das entrevistas na informação dos acordos possíveis;

4) Infraestrutura foi responsável pela organização dos banheiros, da cozinha, a montagem das barracas e os locais das reuniões. Foi responsável pela iluminação;

5) A Comissão da Limpeza foi a responsável por organização do ambiente limpo, com os locais de jogar lixo, escala para a limpeza do pátio e locais de reuniões;

6) A equipe da Formação ficou responsável pelos espaços formativos tanto nos núcleos, como nas brigadas e na coordenação do acampamento, responsável pela organização dos estudos dos materiais do movimento;

7) A equipe da Auto organização - conforme já foi mencionado é formado por Núcleos de Base $^{12}$ (núcleo é um grupo de 10 pessoas ou 10 famílias), em cada núcleo o grupo elege seus coordenadores (um homem e uma mulher) e os responsáveis pelas equipes. A auto-organização é responsável para incentivar a reunião dos núcleos, as escalas da distribuição dos alimentos e da limpeza e, pôr fim,

\footnotetext{
${ }^{12} \mathrm{O}$ núcleo de base são agrupamentos integrados por dez (10) famílias de Assentados ou Acampados que escolhem sua coordenação, composta por um (1) homem e uma (1) mulher, para compor a Coordenação Geral do Assentamento ou Acampamento (MST, 1992).
} 


\section{Revista \\ Debates Insubmissos}

8) O grupo responsável pela realização da Místicas ${ }^{13}$ nas manhas, nas assembleias ou atos políticos.

Todos os dias os acampados na SEDU/ES recebiam visitas diversas, sindicalistas, estudantes, parlamentares, pastorais sociais etc. E, também, entre os acampados surgiu a ideia de constituir uma equipe para visitar as escolas da capital e conversar com a comunidade local acerca dos desafios que eles vivem na cidade.

As negociações foram intensas, primeiro o Secretário Sr. Haroldo Rocha encaminhou uma equipe para saber o que os educadores queriam, depois foi realizada uma audiência com o Secretário adjunto, que nos informou a respeito dos processos que o Secretário pretendia. Depois, iniciamos uma série de negociações com representantes dos pais e educadores junto ao Secretário de Educação e sua equipe e a advogada da SEDU/ES.

Essas audiências não conseguiam avançar e diferentes foram os empecilhos para dar movimento aos trabalhos. Mais de vinte (20) dias se haviam passado até que o Secretário convocou uma reunião na Superintendência de Cariacica e fez o seguinte comunicado: Os educadores que não abririam mão de trabalhar com a Pedagogia da alternância, deixariam sua vaga para uma convocatória de novos educadores que assumiriam esses lugares. Os educadores que abrirem mão da pedagogia da alternância poderiam assinar os contratos.

Esse ultimato acabou por abalar alguns educadores que começaram a fazer campanha interna para que se pudesse suspender o acampamento. Instalando-se, na ocupação feita no pátio da SEDU, duas forças antagônicas e conflituosas: uma a favor da manutenção do acampamento e outra favorecendo o fim da ocupação. Estava posto um grande conflito. Os

\footnotetext{
${ }^{13}$ É uma força impulsionadora que faz mover a militância, sair da sua zona de conforto e empunhar a bandeira de luta e seguir em frente. Essa força está contida a partir dos desejos e sonhos coletivos e faz brotar, nas singularidades, uma energia que enriquece e faz a organização brilhar. Quando se faz o momento da mística é uma representação simbólica, procurando desenvolver os sonhos e possibilidades de realização na realidade atual. Ela traz o colorido e o belo nas encenações e faz o individuo se espelhar nos desejos coletivos. A mística colabora no firmar das subjetividades coletivas revolucionárias. Para Boff (1999) a Mística significa, "[...] o conjunto de convicções profundas, as visões grandiosas e as paixões fortes que mobilizam pessoas e movimentos na vontade de mudanças, inspiram práticas capazes de afrontar quaisquer dificuldades ou sustentam a esperança face aos fracassos históricos". (p. 24).
} 


\section{Revista \\ Debates Insubmissos}

recursos para a manutenção do acampamento estavam esgotando e a escassez de pessoas para fazer a troca, também. Esses fatores colaboraram para que o acampamento na SEDU/ES terminasse.

Foi uma decisão muito difícil de tomar: de um lado a necessidade de continuação do acampamento - a resistência! De outro lado, a necessidade de voltar às aulas e a pressão da demissão. Foram realizados levantamentos e debates nos Núcleos de Base. Mas, não bastava a boa vontade política, era necessário suprir as condições objetivas para continuar constituindo a força coletiva de resistência como invenção. Assim, a decisão foi retornar às escolas e continuar a luta e o trabalho de base, de formação junto às famílias para que, em outro momento, retomássemos a ocupação na SEDU/ES.

Ao final da tarde, por volta das 17 horas, foi convocada uma assembleia geral, com os amigos e entidades apoiadoras para um ato de encerramento e mística. Todos falaram da necessidade de continuidade da luta e da resistência nas escolas e continuar denunciar o descaso do governo Paulo Hartung para com a Educação do Campo.

No final de 2016, a SEDU/ES lançou um edital convocando a todos os docentes que atuavam no campo a fazer uma prova de avaliação, quem conseguisse aprovação, permaneceria nas escolas. Muitos educadores que vinham atuando nas distintas salas das escolas do/no campo foram eliminados, uns por não terem sido aprovados na avaliação, outros por falta de documentação na hora da inscrição, como o CPF, RG e outros, ainda, perderam a vaga por inconsistência de informações em algum documento apresentado como por exemplo, a data de nascimento não ser igual em documentos diferentes. No ato da contratação os funcionários da SEDU/ES olhavam minuciosamente toda a documentação buscando encontrar qualquer falha que pudesse eliminar o Educador Social ${ }^{14}$.

\footnotetext{
${ }^{14}$ Educador Social dito aqui, é o educador que se desloca para a organização social, compreendendo as forças políticas em jogo, fazendo acontecer o movimento social na escola do assentamento e na Reforma Agrária Popular (PETRUS; ROMANS; JAUME, 2003).
} 


\section{Debates Insubmissos}

Revista

Iniciamos o ano escolar de 2017 com desfalque na Educação do Campo no estado: três (3) escolas não tinham secretária no município de São Mateus; as turmas de $5^{\circ}$ ao $9^{\circ}$ ano foram integradas em uma (1) só e, as séries iniciais, também foram reunidas do $1^{\circ}$ ao $5^{\circ}$ ano. O que se alcançou na organização curricular foram três dias de período integral e a inclusão no currículo das disciplinas: Plano de Estudos, Auto-organização, Agroecologia e Educação Familiar.

Assim, os educadores passaram o ano entristecidos e angustiados pois, se quisessem manter os elementos da Pedagogia da Alternância, teriam que se desdobrar para pratica-las e, por outro lado, os educadores que acabavam de chegar, demonstravam não conhecer a realidade das escolas ou sobre a Educação do Campo, o que dificultava a implementação das ferramentas da Pedagogia da Alternância. Em algumas equipes pedagógicas das/nas escolas iniciará embates internos ou denúncias sobre o método de ensino das escolas do campo. Não aceitavam a extensão do tempo para planejar a mística, a auto-organização, o plano de estudos, as atividades de pesquisa e o trabalho agrícola. Esses são elementos essenciais para a existência das escolas do campo, ou seja, são os elementos da Pedagogia da Alternância.

Ainda, no decorrer do ano escolar, os professores começaram a ser denunciadas(os) por suas atividades apresentadas em sala de aula e as tarefas realizadas na escola à Superintendência de Educação que, segundo as alegações, estariam contra o movimento da Educação do Campo. Assim, houve investimento para aproximar os educadores novatos para a compreensão da Educação do Campo e seus elementos de base para sua existência.

Nesse contexto, na Escola Paulo Damião Tristão Purinha, a coordenadora continuou realizando as atividades no Setor de Educação e atividades fora da escola. E na própria escola manteve-se a formação constante dos educadores, cuidando de um clima de amizade e unidade. Organizamos o amigo anjo e buscamos implementar os elementos da Pedagogia da Alternância como: o Plano de Estudo, a Auto-organização dos educadores e educandos e a Prática da Atividade de Pesquisa, assim como o setor agrícola atuou na horta e plantação de roça, juntamente com os educandos e educandas. 


\section{Revista \\ Debates Insubmissos}

Nesse período a escola sofreu algumas tentativas de integração das turmas das séries finais o que não foi possível devido à articulação junto as famílias que barraram a ofensiva da superintendente de Linhares.

Outro aspecto a considerar foi o debate da municipalização da escola. A comunidade escolar conseguiu levar a Superintendente de Educação até a escola para uma reunião onde os educandos e educandas coordenaram e conduziram os trabalhos, solicitando várias pautas, entre elas, a necessidade de continuidade das turmas separadas. A superintendente, ao final do encontro, elogiou o protagonismo dos estudantes e se comprometeu em buscar condições para melhorar as aprendizagens.

A Escola, ainda, sofreu a tentativa de municipalização e, mais uma vez, foram feitas várias articulações até levar a Secretária de Educação do município de Linhares à escola. Nesse dia, a participação dos assentados foi primordial, pais e lideranças expressaram as desvantagens dos processos de municipalização e os motivos pelos quais a comunidade e o assentamento não aceitavam essa política. A Secretária de Educação agradeceu e expressou que não iria insistir com o processo e participou da mística de encerramento plantando uma árvore junto à comunidade escolar.

Como podemos perceber, há uma busca de destruição de uma proposta de Educação do Campo que afirma uma democracia participativa e busca construir um projeto de sociedade em que as necessidades básicas dos seres humanos sejam superadas, propondo uma educação alternativa que esteja a serviço de um bem comum da sociedade.

Quando pensamos no embate das forças até aqui exposto, entre uma Educação do Campo e um projeto comprometido com as forças neoliberais em curso, com um novo redirecionamento do capitalismo, que tem trabalhado na intensa busca de aumento dos lucros, não se importando com as formas de exploração da vida, sentimos a necessidade de perguntarmos: por onde passa a resistência a esta força neoliberal? Como estamos pensando a resistência diante de tamanhas contradições colocadas pelo atual momento vivido no Brasil? 


\section{Revista \\ Debates Insubmissos}

Acreditamos que realizar uma análise acerca das resistências em construção pode favorecer na formulação de políticas alternativas de proliferação da vida. Linhares (2001) nos recorda de uma máxima marxista "tudo o que é sólido se desmancha no ar" e, portanto, a hegemonia da burguesia, vanguarda do atraso vigente no Brasil, não será eterna, muito menos as concepções e as políticas mercantilistas de educação (LINHARES,2001, p. 74).

Segundo a autora, a luta por construção de alternativas para o enfrentamento da produção capitalística, necessariamente deve nos conectar com forças comprometidas com um projeto contra hegemônico, acumulando experiencias e práticas emancipatórias. Essa é uma tarefa revolucionária e "politicamente educativa" que à medida que criamos experiencias, possamos sinalizar que a luta e resistência podem e são transformadoras.

A educação do Campo se configura como força de resistência por suas diversas práticas que tem, na práxis educativa e na democracia participativa, seu grande foco, buscando criar espaços educativos e criativos, contemplando as diversas dimensões da vida e trabalho, impulsionando os educandos à sua formação integral e formando sujeitos para o exercício autônomo e protagonizado. Assim, a resistência se torna necessária para a ampliação dos espaços/tempos em que educação afirme o desejo dos trabalhadores rurais assentados.

A "Escola que queremos" que está na cartilha $\mathrm{n}^{\circ} 01$ do MST, onde as famílias definem o que desejam para as escolas dos/nos assentamentos, para os seus filhos e comunidade, como uma escola da vida, para vivenciar a Pedagogia do Campo, lugar onde vivem e moram, tem sofrido diversos ataques da ideologia da ultradireita brasileira que tem operado, nos primeiros dez meses de mandato, sob a lógica “dividir para governar", tática historicamente usada pelos que detém o poder e que buscam dividir a classe trabalhadora para poder dominar e governar. O exercício da força repressiva do estado tem-se manifestado na escola do assentamento quando gestores escolares dividem a equipe pedagógica, pais e responsáveis de educandos, aproximam estudantes para que estes fiquem com seus educadores na defesa da Educação do Campo.

\section{O QUE TEMOS APRENDIDO NESSA RESISTENNCIA?}




\section{wartete \\ Debates Insubmissos}

No movimento, na luta militante, temos aprendido a expandir a resistência como a planta que rasga o chão, o muro, o cimento, o asfalto, a pedra, as durezas, para florir. E, junto com Heckert (2004), afirmamos essa ampliação da resistência acontece criando permanentemente formas de agir e de relacionar-se conosco mesmo, com a luta por terra e educação e no próprio trabalho de organização no MST.

Na comunidade do assentamento da escola Paulo Damião Tristão Purinha, educadores, educandos, pais, diante do acirramento de práticas de vigilância e de desconfiança no atual momento, organizam e possibilitam, por exemplo, a colocação de outros horários e locais de encontro, para reuniões que fortalecem a gestão democrática da escola da escola.

Os planejamentos individuais, a divisão das tarefas básicas de cuidado e manutenção da escola, o fortalecimento e funcionamento dos setores agropecuário, pedagógico e administrativo, via as práticas de autogestão e auto organização, têm constituído exercícios permanentes de reflexão e ação (via realização de místicas), afirmando a importância de uma educação voltada para a realidade dos próprias(os) educandas(os) que participam e fortalecem permanentemente as reuniões da Regional e do Setor de Educação do próprio MST, afirmando sua "identidade" de militante e, ainda, se fortalecendo na resistência de práticas mercadológicas e individualistas.

Assim, a resistência se vem enraizado com ações concretas e na efetiva realização da autoorganização de todas e todos, na consolidação dos quintais agroecológicos, com a realização das místicas e planos de estudos. As práticas educacionais conectadas com o território, com a potência da vida do campo, com as possibilidades da ampliação da produção agroecológica, têm-se constituído em exercícios potentes na constituição de processos formativos.

A mística tem-se mostrado como uma atividade aglutinadora, contribuindo para o fortalecimento das relações entre educandos e educadores quando os reúne em torno de um ato intensivo, onde a emoção, memória e experiência são integradas no exercício de pensar/sentir as possibilidades existentes na luta pela vida. 


\section{Revista \\ Debates Insubmissos}

A auto-organização tem contribuído na organização básica dos educandos, debate e decisões coletivas, na distribuição das tarefas e no planejamento de suas atividades. Entretanto, a auto-organização entre os educadores da escola não tem sido praticada desde que a atual gestão pedagógica a compreendido como uma "ação ideológica do MST" e não um conteúdo programático da escola básica. No enfrentamento a este entendimento, os docentes, estudantes e comunidade do assentamento tem insistido para que se cumpra o Edital 65 que afirma a necessidade de alocar professores nas escolas do campo que atuem em consonância com a realidade camponesa.

O trabalho produtivo, a agroecologia, vem sendo implementada paulatinamente, a partir dos quintais produtivos que são espaços ou área para plantar, organizar uma horta. Na escola que se orienta pelos princípios da Educação do Campo, a cada turma destina-se uma área específica e, cada estudante dessa turma, acompanha a semeadura, crescimento e colheita das plantas. Nessa experiência o estudante é convidado a escrever o que tem observado e, ao final do processo, a fazer uma apresentação do seu trabalho publicamente. Nessa prática vive-se e afirma-se a experiencia e existência camponesa.

Nos Planos de Estudos, que nada mais é do que uma prática de pesquisa em que os estudantes, a partir de temas geradores, apreendem conhecimentos acumulados pela humanidade e que podem colaborar no fortalecimento da comunidade, na medida em que podem auxiliar na tomada de decisões diante situações problemas que possam enfrentar.

Finalmente, ao olharmos para essas diferentes ações acima relatadas, nos deparamos com um permanente exercício de produção de diversas ações que nada mais fazem do que ampliar nosso presente e, nesse processo, expandir a resistência como criação incansável de práticas que desafiam à forma como temos sido (FOUCAULT, 1984). E, ao ampliar o presente deslocamos nosso olhar do futuro e focamos no que nos acontece no dia-a-dia porque, junto com Freire (2000) afirmamos que "o futuro não nos faz. Nós é que nos refazemos na luta para fazê-lo", ou seja, nossa constituição e a constituição da resistência se faz na luta e é nesse exercício que nos refazemos e existimos. 


\section{REFERÊNCIAS}

ARPINI, Naiara. Justiça exige a reabertura de escolas, mas governo do ES nega fechamento. Fátima. A Gazeta. 10 de março de 2016. Disponível em: http://g1.globo.com/espiritosanto/educacao/noticia/2016/03/justica-exige-reabertura-de-escolas-mas-governo-do-es-negafechamento.html. Acesso em 22 de outubro de 2019.

BARROS, Laura Possana. e KASTRUP, Virgínia. Cartografar é acompanhar processos. Pistas do método da cartografia: pesquisa-intervenção e produção de subjetividade. Porto Alegre: Sulina, 2009.

BOFF, Leonardo. Mística e espiritualidade. $6^{\text {a }}$ - ed. Rio de Janeiro, Garamond, 2005.

CALDART, Roseli S. A pedagogia do Movimento Sem Terra: Escola é mais do que escola. Petrópolis: Vozes, 2000.

CALDART, Roseli Salete; PEREIRA, Izabel Brasil; ALENTEJANO, Paulo; GRIGOTTO, Gaudencio. Dicionário da Educação do Campo. Expressão Popular, Rio de Janeiro -São Paulo 2012.

CARDOSO, J. P. de F. e SANTOS, J. C. A. dos. Fechamento de escolas e do desenvolvimento no campo no estado do Espírito Santo. Anais do III Seminário

Federalismo e Políticas Educacionais. UFES, Vitória, 31 de novembro de 2018, pp. 292298.

EEEF PAULO DAMIÃO TRISTÃO PURINHA. Caderno De Reflexão. Linhares, 2018.

ESPÍRITO SANTO EM AÇÃO. Plano de desenvolvimento: Espírito Santo em Ação 2030. Vitória, 2013. Disponível em:

https://sesp.es.gov.br/Media/sesp/Plano\%20ES\%202030/Plano\%20de\%20Desenvolvimento\% 20ES\%202030.pdf Acesso em 22 de outubro de 2019.

FOUCAULT, Michel. A arqueologia do saber. Rio de Janeiro: Forense Universitária, 1986.

FOUCAULT, Michel. As palavras e as coisas: uma arqueologia das ciências humanas. $9^{\mathrm{a}} \mathrm{Ed}$. São Paulo, Martins Fontes, 2007.

FOUCAULT, Michel. História da sexualidade 2: o uso dos prazeres. Rio de Janeiro, Graal, 1984. Vol.2.

FOUCAULT, Michel. Vigiar e punir. Petrópolis: Vozes, 1983.

FREIRE, Paulo. Pedagogia da Esperança. São Paulo, Brasiliense, 1992.

FREIRE, Paulo. Pedagogia da indignação. São Paulo, UNESP, 2000. 
FRIGOTTO, Gaudêncio (Org.) Escola "sem partido": esfinge que ameaça a educação e a sociedade brasileira. Rio de Janeiro: LPP/UERJ, 2017.

HECKERT, Ana Lucia Coelho. Narrativas de resistência: educação e políticas. Tese apresentada no Programa de Pós-Graduação de Psicologia da Universidade Federal Fluminense, 2004.

JORNAL SINDICAL. Movimentos sociais deixam prédio da Secretaria de Educação do ES. 11 de março 2016.

JORNAL SINDICAL. Ocupação da SEDU no ES: MST aposta em formação e diálogo com a sociedade como forma de resistência. 25 de fevereiro de 2016.

LINHARES, Célia Frazão Soares. Os Professores e a Reinvenção da Escola: Brasil e Espanha. São Paulo: Cortez, 2001.

MOVIMENTO DOS TRABALHADORES RURAIS SEM TERRA. Como fazer a escola que queremos: planejamento. Porto Alegre: MST, 2005. Caderno de Educação nº6.

MOVIMENTO DOS TRABALHADORES RURAIS SEM TERRA. Sem Terra ocupam SEDU após secretário ignorar pauta sobre educação. Site do MST. Disponível em: http://www.mst.org.br/2016/02/17/sem-terra-seguem-ocupando-sedu-do-es.html. Capturado em: 10 de setembro de 2019.

NOGUEIRA, Ítalo. Governador que só pensa em morte reclama sobre política sobre caixão. Folha de São Paulo. 23 de setembro de 2019, Opinião. Disponível em: https://www1.folha.uol.com.br/cotidiano/2019/09/governador-que-so-pensa-em-mortereclama-de-politica-sobre-caixao.shtml.

OLIVEIRA JUNIOR, Rui Barbosa de. As políticas educacionais do segundo mandato do governo Paulo Hartung e seus impactos no trabalho docente. Dissertação de Doutorado. UFES. 2016.

OLIVEIRA, Ueber José de; e LIRIO, Marcos Marcelo. O projeto escola viva: a política de educação neoliberal de Paulo Hartung no Espírito Santo (2003-2016). Disponível:

https://periodicos.ufpe.br/revistas/revistaclio/article/view/25043.

PACHECO, Lucy Mari Duso. Pedagogia da Alternância: Práticas Educativas escolares de enfrentamento da exclusão social no meio rural. Curitiba, Editora CRV, 2016.

PASSOS, Eduardo. e BARROS, Regina Barros. A cartografia como método de pesquisaintervenção. In: PASSOS, E.; KASTRUP, V.; ESCÓSSIA, L. da. Pistas do método da cartografia: pesquisa-intervenção e produção de subjetividade. Porto Alegre: Sulina, 2009, p. $17-31$

ROMAGNOLI, Roberta Carvalho e PAULON, Simone Mainieri. Escritas Implicadas, Pesquisadores implicantes: notas sobre os destinos da subjetividade nos desatinos da 
produção científica In: DIMENSTEIN, Magda; LEITE, Jader Ferreira. Psicologia em Pesquisa: cenários de práticas e criações. Natal, RN: EDUFRN, 2014.

ROMANS, Mercès; PETRUS, Antoni; TRILLA, Jaume. Profissão educador social. Porto Alegre: Artmed, 2003.

SADER, Emir (org.) O Brasil que queremos. Rio de Janeiro: UERJ, 2016.

SINGER, André. Para onde vai a democracia? O Brasil 30 anos após a constituição de 1988. Anais do III Seminário Federalismo e Políticas Educacionais. UFES, Vitória, 31 de novembro de 2018.

Recebido: $23 / 03 / 2021$

Aprovado: 04/12/2021 